DOI: https://doi.org/10.47405/mjssh.v6i8.938

\begin{tabular}{|c|c|}
\hline 4 & Malaysian Journal of Social Sciences and Humanities (MJSSH) \\
\hline $\begin{array}{l}\text { Malaysian Juoural of } \\
\text { Social ccciecces and }\end{array}$ & Volume 6, Issue 8, August 2021 \\
\hline (MJ-sSH) & e-ISSN : 2504-8562 \\
\hline & $\begin{array}{l}\text { Journal home page: } \\
\text { www.msocialsciences.com }\end{array}$ \\
\hline
\end{tabular}

\title{
Determining Barriers Factors That Affecting Indonesian Young Customer Purchase Intention of Sustainable Fashion
}

\author{
Muhamad Naufal Alfauzy ${ }^{1}$, Arfenia Nita1 \\ ${ }^{1}$ School of Business and Management, Institut Teknologi Bandung, Indonesia \\ Correspondence: Muhamad Naufal Alfauzy (naufal_alfauzy@sbm-itb.ac.id)
}

\begin{abstract}
This research aims to generate the correlation between several barrier factors: product design barrier, knowledge barrier, cost barrier, and supply source barrier towards Gen-Y customer purchase intention of sustainable fashion in Indonesia. This research is using the theory that stated barrier factors are directly influencing customer purchase intention. A total of 226 respondents all across Indonesia are selected through the non-probability purposive sampling technique. This study's instrument uses questionnaires that have been adjusted in terms of language and evaluated by using validity and reliability testing. The data output from data collection is analyzed with the multiple linear regression techniques. The findings indicate a significant influence between product design barriers, knowledge barriers, cost barriers, and supply source barriers simultaneously towards purchase intention of sustainable fashion among Indonesian Gen-Y. When assessed partially, product design barriers negatively influence purchase intention, and the result is significant. It means that the product design barrier is not a barrier that hinders the purchase intention of sustainable fashion. The knowledge barrier and cost barrier also negatively influence purchase intention of sustainable fashion, but the result is not significant. The supply source barrier has a positive influence on the purchase intention of sustainable fashion. It means there is an actual barrier that hinders the purchase intention of sustainable fashion. This study suggested that business owners make sustainable fashion more accessible on every platform, offline and online, to decrease the supply source barrier.
\end{abstract}

Keywords: product design barrier, knowledge barrier, cost barrier, supply source barrier, purchase intention, sustainable fashion

\section{Introduction}

In recent years, the fashion industry is overwhelmed by fast fashion products and emerging and expanding brands. Fast fashion becomes a problem because of the ever-changing trends and fashion tastes of customers. The company uses unsustainable methods to cope with trends and demand (Kim et al., 2018; Mcneill \& Moore, 2015). Because of this, the fashion product life cycle has become faster and faster; this also leads to high consumption of fashion products and leads to high fashion waste disposal to the environment (Mcneill \& Moore, 2015; Niinimäki et al., 2020; Wagner \& Heinzel, 2020). The harmful environmental impact caused by the fashion industry pushing fashion industry itself to improve its sustainability in business to create an alternative model for fast fashion (Kong et al., 2016; Niinimäki et al., 2020) 
Sustainable and ethical fashion valued at $\$ 6,345.3$ million in 2019 with a compound annual growth rate (CAGR) of $8.7 \%$ since 2015; in 2023, the market of sustainable and ethical fashion is expected to increase to $\$ 8,246.1$ million with a compound annual growth rate (CAGR) of $6.8 \%$ (L. wood, 2021). Compared to sustainable and ethical fashion, fast fashion valued at $\$ 35.8$ billion in 2019 and decline in 2020 with $\$ 31.4$ billion in 2020 at a compound annual growth rate (CAGR) of $-12.32 \%$ due to covid19 , the industry is expected to increase in 2023 with $\$ 38.21$ billion at CAGR of 6.7\% (L. wood, 2020).

The Researcher wants to know why sustainable fashion is so far apart compared to the fast fashion industry. The Researcher also found a problem in sustainable fashion business when talking to business owners and members. One of them is the Farven company. The product of sustainable fashion is hard to sell although offered to many potential customers. $90 \%$ of customers said that the cost is too high, and some did not like the model. In the end, potential consumers are still hesitant to buy the product when offered sustainable or eco-friendly clothing. Consumers have been reluctant to change their consumption choices to adopt sustainable products (Mcneill \& Moore, 2015). This consumer behavior means that there is a barrier that blocks consumers from buying sustainable fashion products.

In this study, product design barriers, knowledge barriers, cost barriers, supply source barriers, and purchase intention will be used as variables to generate more information regarding the correlation between barrier factors and Gen-Y purchase intention of sustainable fashion in Indonesia. The Researcher focuses on Gen-Y with an age range of 19-39 years old because people tend to know information better in social media and other media. at that age

\section{Literature Review}

\section{Purchase Intention}

Purchase intention can be defined as the probability that the customer will buy a product or service. Sustainable fashion customer purchase intention begins with awareness of social problems and awareness of new fashion (Gam, 2011). Customers see that fashion brands' social sustainability can make a positive brand relationship between a sustainable fashion brand and the customer itself (Park \& Kim, 2016). A positive Brand relationship can lead to a good brand image, and a good brand image can increase purchase intention (Chang \& Jai, 2015; Park \& Kim, 2016).

\section{Product Design Barrier}

A product design barrier can be defined as something that was blocking customers in terms of product design. Sustainable fashion product design barrier can be seen as sustainable fashion would not look good, perception of the fashion is harsh on the fabric, and the fabric seems fragile and wouldn't last long (Connell, 2010; Mcneill \& Moore, 2015). Other than that, it is a common perception that customers see sustainable fashion as unattractive, have poor quality, unsuitable color, and don't fit their fashion style (Myers, 2014; Ozdamar Ertekin \& Atik, 2015). All of this bad perception because there are negative stigma and stereotypes among customers and designers about sustainable clothing (Harris et al., 2016). This stigma is often to mention that the design of sustainable fashion is a counter-culture, subculture, and not for the majority of people that are conscious about their style of fashion (Connell, 2010). The stigma is mainly associated with the hippy movement, leading to an outdated image; this is a significant barrier when adopting sustainable fashion (Moon et al., 2015; Winge, 2008).

Other than hippy, the stigma of sustainable fashion is exclusive in terms of design and targeting higherincome consumers; this stigma will lead to sustainable fashion remain in a limited and small group of rich customers, not affordable for the masses (Ozdamar Ertekin \& Atik, 2015; Winge, 2008). Because of product design that counters culture and does not fit mainstream customers, the purchase intention is low, and the product is hard to acquire (Connell, 2010). 


\section{Knowledge Barrier}

A knowledge barrier can be defined as something that blocks customers in terms of knowledge. Consumers generally have little knowledge about the negative impact of fashion production and acquiring sustainable fashion (Connell, 2010; Moon et al., 2015). Other than the customer, people in the fashion industry find it hard to distinguish what sustainable fashion and production are (Moon et al., 2015). Misunderstanding in comprehending the environmental impact of fashion production is also a barrier because consumers believe the wrong idea about Sustainable fashion and basing their decision on misinformation (Connell, 2010). The information that fashion brands provide is implicit; fashion brands must provide explicit and transparent information (Harris et al., 2016; Mcneill \& Moore, 2015). Consumers also did not know what material and resources sustainable fashion is made from; this is the sign that fashion producers and brands lack transparency (Connell, 2010; Harris et al., 2016). The consumer also did not know what environmentally preferable alternative fiber besides organic cotton and hemp (Connell, 2010).

\section{Cost Barrier}

A cost barrier can be defined as something that blocks customers in terms of cost or price. In the sustainable fashion context, the high price of sustainable fashion, especially eco-friendly clothing, is because of its environmentally safe material and lengthy process of making the clothing (Moon et al., 2015). But not all customers agreed with this idea and were not willing to pay high prices for sustainable fashion (Connell, 2010; Moon et al., 2015; Myers, 2014). Customer perception is that sustainable and ethically produced fashion is too expensive compared to stylish and cheapest available fashion choice (Harris et al., 2016; Myers, 2014).

Many consumers also stated that they want to buy sustainable fashion, but the price is too high because of financial constraints (Connell, 2010). But there are some biases in customers because if customers like a piece of cloth, they will find a way to purchase it regardless of the price (Mcneill \& Moore, 2015). In the end, higher prices in sustainable clothing will remain until there is a notable increase in terms of demands (Connell, 2010).

\section{Supply Source Barrier}

A supply source barrier can be defined as something that blocks customers in terms of supply source and accessibility. Sustainable fashion availability is not yet mainstream for the general customer (Myers, 2014). This phenomenon is caused by limited information and knowledge about Sustainable fashion and the environmental impact caused by fashion production among consumers and producers (Connell, 2010; Myers, 2014). This availability barrier is divided into two, first the availability of sustainable material and finding desired attributes on sustainable fashion (Connell, 2010).

The source of sustainable material is hard to find because mainstream material produced uses pesticides and high intensive on water or does not have access to sustainable material (Connell, 2010). The availability caused by attributes is low because there are just one model and some colors; other than that, the product categories that have sustainable products in it are limited and do not have many sizes that fit the customer; in the end, there are limited options for customers to buy (Connell, 2010). Other than that consumer is hard to find a marketplace or fashion shop that provide sustainable fashion (Moon et al., 2015)

\section{Conceptual Framework}

The Researcher examines and elaborating the variable that will be researched; the variable is the barrier of sustainable fashion and purchase intention for sustainable fashion customers. The barrier is product barrier, knowledge barrier, cost barrier, and supply source barrier. 
DOI: https://doi.org/10.47405/mjssh.v6i8.938

Figure 1: Research Conceptual Framework

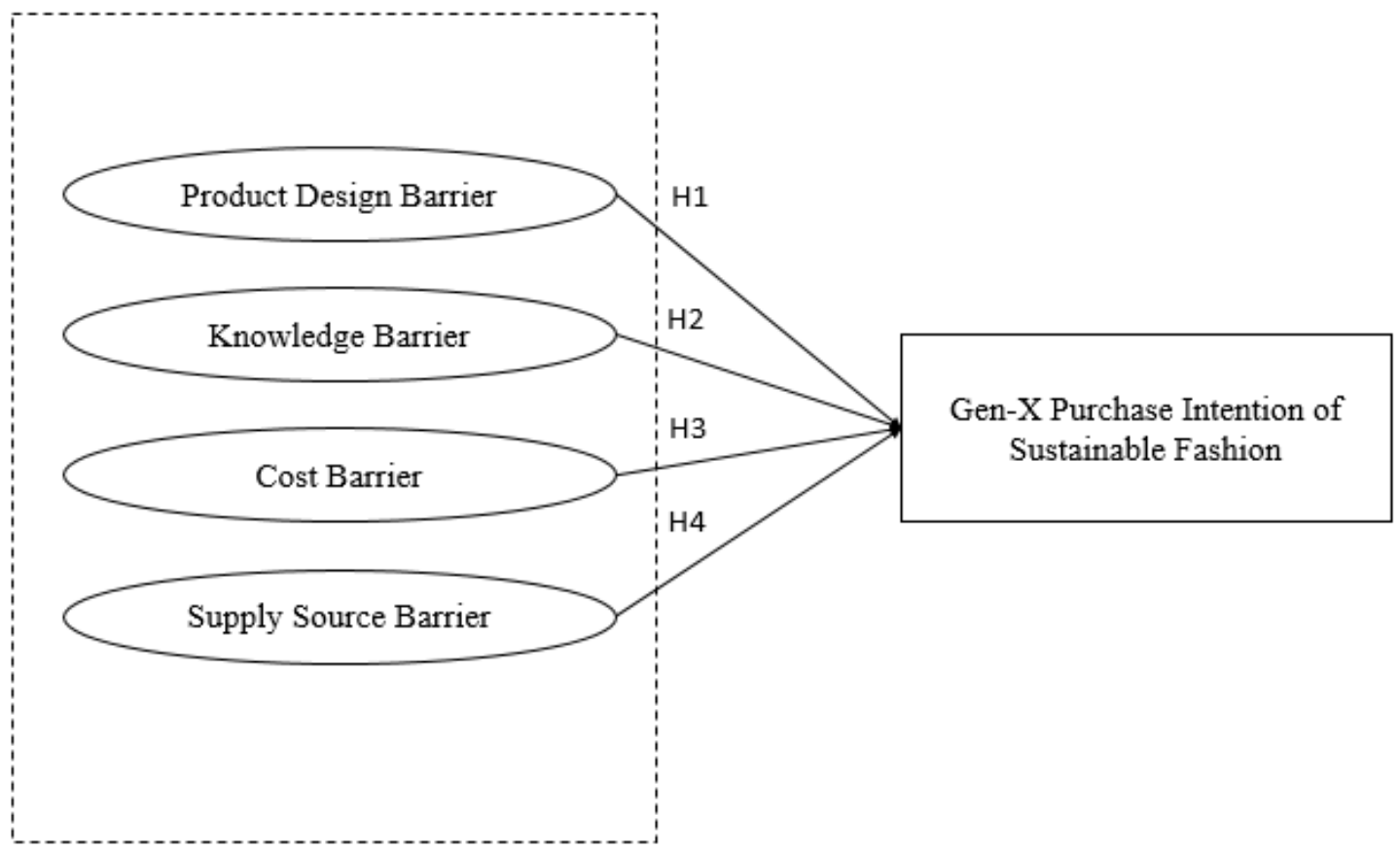

\section{Research Hypothesis}

Below is the set of hypotheses that reflect the relationship about barriers towards purchase intention of sustainable fashion:

H1: Product design barrier positively influence the Gen - Y purchase intention of sustainable fashion

H2: Knowledge barrier positively influence the Gen - Y purchase intention of sustainable fashion

H3: Cost barrier positively influence the Gen - Y purchase intention of sustainable fashion

H4: Supply source barrier positively influence the Gen - Y purchase intention of sustainable fashion

\section{Methodology}

This research collected the data using a survey design method by providing a questionnaire to the designated respondents. The questionnaire is divided into six parts. The first is a sociodemographicrelated question, part two until part six is related to the barrier variable (product design barrier, knowledge barrier, cost barrier, supply source barrier) and purchase intention. A validity and reliability test of the construct was conducted. The table below is the result of validity testing.

Table 1 : Validity Test Result

\begin{tabular}{llcccc}
\hline \multicolumn{1}{c}{ Construct } & Item & Sig & Calculated R & R Table & Validity \\
\hline Design & DP1 & 0.05 & 0.776 & 0.129965072 & valid \\
Product & DP2 & 0.05 & 0.817 & 0.129965072 & valid \\
barrier & DP3 & 0.05 & 0.82 & 0.129965072 & valid \\
& DP4 & 0.05 & 0.728 & 0.129965072 & valid \\
& DP5 & 0.05 & 0.781 & 0.129965072 & valid \\
& DP6 & 0.05 & 0.694 & 0.129965072 & valid \\
\hline Knowledge & KW1 & 0.05 & 0.732 & 0.129965072 & valid
\end{tabular}


DOI: https://doi.org/10.47405/mjssh.v6i8.938

\begin{tabular}{lccccc} 
barrier & KW2 & 0.05 & 0.711 & 0.129965072 & valid \\
& KW3 & 0.05 & 0.786 & 0.129965072 & valid \\
& KW4 & 0.05 & 0.777 & 0.129965072 & valid \\
& KW5 & 0.05 & 0.751 & 0.129965072 & valid \\
& KW6 & 0.05 & 0.625 & 0.129965072 & valid \\
\hline Cost barrier & KW7 & 0.05 & 0.294 & 0.129965072 & valid \\
& CT1 & 0.05 & 0.748 & 0.129965072 & valid \\
& CT2 & 0.05 & 0.837 & 0.129965072 & valid \\
\hline Supply & CT3 & 0.05 & 0.857 & 0.129965072 & valid \\
Source barrier & SS1 & 0.05 & 0.699 & 0.129965072 & valid \\
& SS2 & 0.05 & 0.654 & 0.129965072 & valid \\
& SS3 & 0.05 & 0.798 & 0.129965072 & valid \\
& SS4 & 0.05 & 0.725 & 0.129965072 & valid \\
\hline Purchase & SS5 & 0.05 & 0.656 & 0.129965072 & valid \\
Intention & PI1 & 0.05 & 0.814 & 0.129965072 & valid \\
& PI2 & 0.05 & 0.786 & 0.129965072 & valid \\
& PI3 & 0.05 & 0.862 & 0.129965072 & valid \\
& PI4 & 0.05 & 0.73 & 0.129965072 & valid \\
& PI5 & 0.05 & 0.691 & 0.129965072 & valid \\
& PI6 & 0.05 & 0.718 & 0.129965072 & valid \\
\hline
\end{tabular}

Table 1 is the result validity result. In table 1 , all the items in each variable are concluded as valid because the calculated $\mathrm{R}$ of every item exceeds the table $\mathrm{R}$ for 226 respondents $(0.129965072)$. There is no need for adjustment to the variables so the Researcher can progress to process the data. The highest validity for the item is item PI 3 with the question "I plan to purchase and wear sustainable/ecofriendly fashion products in the future." The lowest validity is for item KW7 with the question "I think some of Fashion Brand hiding its bad impact and did not show their data as a part of nontransparency," but all of the items are considered valid.

Table 2 : Reliability Test Result

\begin{tabular}{lcc}
\hline Variable & Cronbach Alpha $(\boldsymbol{\alpha})$ & Status \\
\hline Purchase Intention of Sustainable & 0.857 & Reliable \\
Fashion & & \\
Product Design Barrier & 0.859 & Reliable \\
Knowledge Barrier & 0.8 & Reliable \\
Cost barrier & 0.747 & Reliable \\
Supply Source Barrier & 0.748 & Reliable \\
\hline
\end{tabular}

Table 2 is the result of a reliability test. In this table, the Researcher concluded that all the variables are reliable because the Cronbach alpha of all the variables exceeds 0.7 or 0.6 for exploratory research (Hair et al., 2014). It can be considered that all of the variables are consistent with the higher Cronbach alpha in this research is 0.859 for the design product variable and 0.747 for the cost barrier variable.

\section{Result and Discussion}

The Researcher has already done the classical assumption test. The result is the data fulfilled the required assessment for the classical assumption test. The data is normally distributed, with no multicollinearity between each variable, no autocorrelation, and no heteroscedasticity. After that, the Researcher uses multiple linear regression with five variables, product design barrier (PD), knowledge barrier (KB), cost barrier (CB), supply source barrier (SS), and purchase intention (PI). The result is product design barrier (PD), knowledge barrier $(\mathrm{KB})$, and cost barrier $(\mathrm{CB})$ have a negative correlation or influence towards Purchase intention (PI). Supply source barriers (SS) positively correlate to Purchase Intention (PI); it means that only supply source barriers indeed become a barrier that blocks customers from purchasing sustainable fashion products. 
Table 3 : Multiple Linear Regression Result

\begin{tabular}{|c|c|c|c|c|}
\hline Model & Estimate & Coefficient Std. error & t-Value & Sig \\
\hline (Intercept / Constant) & 25.858 & 1.633 & 15.830 & 0.000 \\
\hline Product Design Barrier (PI & I -0.251 & 0.062 & -4.060 & 0.000 \\
\hline $\begin{array}{l}\text { Knowledge Barrier (KB) } \\
\text { Cost Barrier (CB) }\end{array}$ & $\begin{array}{l}-0.086 \\
-0.096\end{array}$ & $\begin{array}{l}0.050 \\
0.120\end{array}$ & $\begin{array}{l}-1.719 \\
-0.795\end{array}$ & $\begin{array}{l}0.087 \\
0.427\end{array}$ \\
\hline Supply Source barrier (S & 0.087 & 0.087 & 2.941 & 0.004 \\
\hline
\end{tabular}

From table 3, the equation can be concluded like this :

$$
\mathrm{PI}=25.858-0.251 \mathrm{PD}-0.086 \mathrm{~KB}-0.096 \mathrm{CB}+0.254 \mathrm{SS}+\varepsilon
$$

The interpretation of this equation is that when all independent variables are zero, the constant or GenY Purchase Intention (PI) of sustainable fashion will have 25.858 in value. Every addition of one value of the product design Barrier (PD) will affect gen-Y Purchase Intention (PI) for negative 0.251 assuming that all variables are constant. Every addition of one value of Knowledge Barrier (X2) will affect gen-Y Purchase Intention (PI) for negative 0.086, assuming that all variables are constant. Every addition of one value of Cost Barrier (X3) will affect gen-Y Purchase Intention (PI) for negative 0.096, assuming that all variables are constant. The last is every addition of one value of the Design product Barrier (X1) will affect gen-Y Purchase Intention (PI) for positive 0.254 with the assumption that all variables are constant.

To know if the independent variable is significant partially towards the dependent variable, the sig value of the table must be lower than 0.05 or $5 \%$. The result showed that the independent variable product design barrier (PD) and supply source barrier (SS) is significant because the value is less than 0.05. for the knowledge and cost barrier, the significant value is higher than 0.05 , so this independent variable is insignificant to the dependent variable. Instantaneously hypothesis for Knowledge barrier $(\mathrm{KB})$ and Cost Barrier (CB) is not supported because it is insignificant, and variable product design barrier (PD) and supply source barrier (SS) can continue for hypothesis testing.

Table 4: Partial Hypothesis Testing Result

\begin{tabular}{|c|c|c|c|c|c|}
\hline Hypothesis & Structural Path & Std. error & t-Value & Sig & Status \\
\hline H1 & $\begin{array}{l}\text { Product Design Barrier }(\mathrm{PD}) \rightarrow \text { Gen } \\
\text { Y Purchase Intention of Sustainable } \\
\text { Fashion }\end{array}$ & 0.062 & -4.060 & 0.000 & $\begin{array}{l}\text { Rejected } \\
\text { (Because } \\
\text { negative } \\
\text { sign) }\end{array}$ \\
\hline $\mathrm{H} 2$ & $\begin{array}{l}\text { Knowledge Barrier }(\mathrm{KB}) \rightarrow \text { Gen } \mathrm{Y} \\
\text { Purchase Intention of Sustainable } \\
\text { Fashion }\end{array}$ & 0.050 & -1.719 & 0.087 & Rejected \\
\hline $\mathrm{H} 3$ & $\begin{array}{l}\text { Cost Barrier }(\mathrm{CB}) \rightarrow \text { Gen Y Purchase } \\
\text { Intention of Sustainable Fashion }\end{array}$ & 0.120 & -0.795 & 0.427 & Rejected \\
\hline $\mathrm{H} 4$ & $\begin{array}{l}\text { Supply Source Barrier }(\mathrm{SS}) \rightarrow \text { Gen Y } \\
\text { Purchase Intention of Sustainable } \\
\text { Fashion }\end{array}$ & 0.087 & 2.941 & 0.004 & Accepted \\
\hline
\end{tabular}

Hypothesis 1 is supported in terms of sig value, but the sign of multiple regression is negative, so the product design barrier is not affecting purchase intention positively. The Researcher compares the description analysis and the result of multiple regression and finds out that the respondents disagree with the product design barrier. The reason is respondents think that not all sustainable fashion product designs do not look good, are harsh, not suitable for them, are unattractive, and did not last long. Some of the sustainable fashion is adjusting with market needs and wants also following trends. The 
conclusion is the product design barrier is not affecting the purchase intention of the customer positively. For Hypothesis 2, the variable is not significant enough to affect the purchase intention of sustainable fashion. However, the relationship between purchase intention of sustainable fashion and knowledge barrier is negative, which means the influence is still negative but not that significant. Knowledge barriers variables have no significant negative influence because two aspects of the knowledge barrierr negate each other. The first is knowledge about the impact of fast fashion and sustainable fashion on the environment. The second is about knowledge of product information. The respondents seem to know the effect of fast fashion and sustainable fashion on the environment, making the relationship between the barrier and purchase intention negative. For the second aspect, the respondent does not know about sustainable fashion information, so the relationship between barriers and purchase intention is positive. But when the Researcher calculated, the respondent is leaning towards barriers negatively influencing purchase intention of sustainable fashion, albeit not significant. For Hypothesis 3, the variable is not significant, and the relationship is negative between the independent and dependent variables. This result is possible because the respondent sees the cost as not that significant, but the utility and the model fit the respondent. For hypothesis 4 , the variable is significant and positively influences supply source barrier and purchase intention of sustainable fashion. This result assures that there is a supply source barrier that affects the respondent's purchase intention. This result is because the lack of access, information, and supply of sustainable fashion lead the respondent to hardly notice and get information of sustainable fashion. In the end, the supply source barrier is created.

To know the independent variable's significance towards the dependent variable, the Researcher must run an $\mathrm{F}$ test. According to table 5, The $\mathrm{F}$ value is 7.683 . To know if the independent variable is significant to the dependent variable. The counted $\mathrm{F}$ value must be higher than the $\mathrm{F}$ table, and the ANOVA sig value must be lower than 0.05

Table $5: \mathrm{F}$ test Result

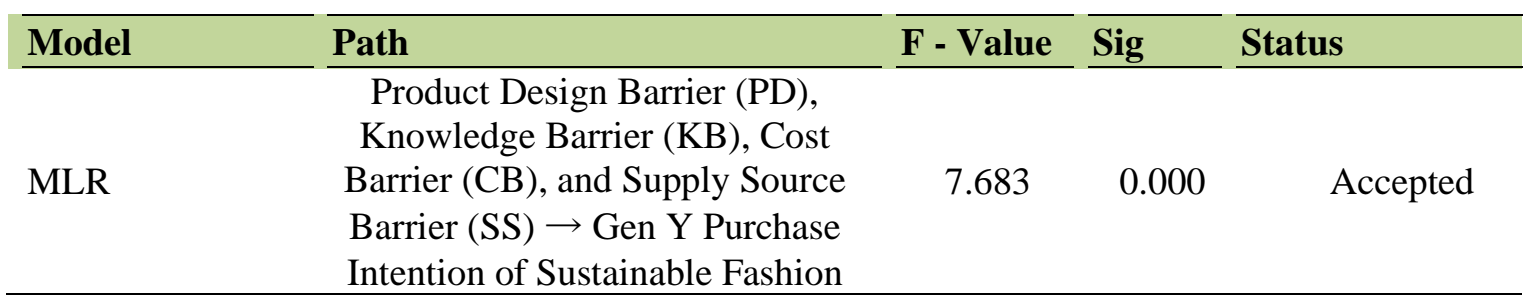

The F Table value for 226 respondents is $F_{-}(0.05:(226-4-1))=2.41$. It means that the F Value : 7.683 is higher than $\mathrm{F}$ table value : 2.41 ( $\mathrm{F}$ value $>\mathrm{F}$ table ; $7.683>2.41$ ) and the sig value is lower than 0.05 $(0.00<0.05)$. two out of two requirements are passed, because of that the result can be concluded that : The model is significant enough, and all independent variables can simultaneously influence the customer purchase intention of sustainable fashion.

According to hair (Hair et al., 2014), coefficient of determination measures the amount of the variance of the dependent variable about it mean that is explained by the independent variables. The coefficient can differ between 0 and 1 . If the regression model is properly used and approximated, the Researcher can assume that the higher the value of R-squared, the greater the explanatory power of the regression equation.

Table 6 : Coeffcient Of Determination Result

\begin{tabular}{llll} 
Model & Residual Std. Error & $\begin{array}{l}\text { Multiple R- } \\
\text { Squared }\end{array}$ & $\begin{array}{l}\text { Adjusted R- } \\
\text { Squared }\end{array}$ \\
MLR & 3.705 & 0.122 & 0.106 \\
\hline
\end{tabular}

In table 6 , The R-squared of the independent variable is 0.122 , which means the barriers variable predicts around $12,2 \%$ of the variations in the customer purchase intention of sustainable fashion. This 
result indicates that there is a need for more barriers variable that must be explored to increase the Rsquared in the next research.

\section{Conclusion}

In this research, the Researcher synthesizes four barriers from the previous study. The barriers are the product design barrier (PD), knowledge barrier (KB), cost barrier (CB), and supply source barrier (SS). 2 barriers did not become significant. They did not affect much of the business implication. The barriers are knowledge and cost barriers. The other two significant variables are the product design barrier and supply source barrier. Amongst the four variables, the relationship is all negative except the supply source barrier. It means the barrier that truly affects purchase intention is the supply source barrier. The product design barrier is also significant, but the effect is countering the supply source barrier or product design barrier is not a barrier; it can be advantageous.

\section{References}

Chang, H. J. J., \& Jai, T. M. C. (2015). Is fast fashion sustainable? the effect of positioning strategies on consumers' attitudes and purchase intentions. Social Responsibility Journal, 11(4), 853-867. https://doi.org/10.1108/SRJ-07-2014-0095

Connell, K. Y. H. (2010). Internal and external barriers to eco-conscious apparel acquisition. International Journal of Consumer Studies, 34(3), 279-286. https://doi.org/10.1111/j.14706431.2010.00865.x

Gam, H. J. (2011). Are fashion-conscious consumers more likely to adopt eco-friendly clothing? Journal of Fashion Marketing and Management, 15(2), 178-193. https://doi.org/10.1108/13612021111132627

Hair, J., Black, W., Babin, B., \& Anderson, R. (2014). Multivariate Data Analysis. In Pearson New International Edition (seventh ed). pearson education limited. https://doi.org/10.4324/9781351269360

Harris, F., Roby, H., \& Dibb, S. (2016). Sustainable clothing: Challenges, barriers and interventions for encouraging more sustainable consumer behaviour. International Journal of Consumer Studies, 40(3), 309-318. https://doi.org/10.1111/ijcs.12257

Kim, J., Park, J., \& Glovinsky, P. L. (2018). Customer involvement, fashion consciousness, and loyalty for fast-fashion retailers. Journal of Fashion Marketing and Management, 22(3), 301316. https://doi.org/10.1108/JFMM-03-2017-0027

Kong, H. M., Ko, E., Chae, H., \& Mattila, P. (2016). Understanding fashion consumers' attitude and behavioral intention toward sustainable fashion products: Focus on sustainable knowledge sources and knowledge types. Journal of Global Fashion Marketing, 7(2), 103-119. https://doi.org/10.1080/20932685.2015.1131435

Mcneill, L., \& Moore, R. (2015). Sustainable fashion consumption and the fast fashion conundrum: Fashionable consumers and attitudes to sustainability in clothing choice. International Journal of Consumer Studies, 39(3), 212-222. https://doi.org/10.1111/ijcs.12169

Moon, K. K. L., Lai, C. S. Y., Lam, E. Y. N., \& Chang, J. M. T. (2015). Popularization of sustainable fashion: barriers and solutions. Journal of the Textile Institute, 106(9), 939-952. https://doi.org/10.1080/00405000.2014.955293

Myers, G. (2014). The nice consumer: Toward a framework for sustainable fashion consumption in the EU. Circulation, 701, 8888.

Niinimäki, K., Peters, G., Dahlbo, H., Perry, P., Rissanen, T., \& Gwilt, A. (2020). The environmental price of fast fashion. Nature Reviews Earth \& Environment, 1(4), 189-200. https://doi.org/10.1038/s43017-020-0039-9

Ozdamar Ertekin, Z., \& Atik, D. (2015). Sustainable Markets: Motivating Factors, Barriers, and Remedies for Mobilization of Slow Fashion. Journal of Macromarketing, 35(1), 53-69. https://doi.org/10.1177/0276146714535932

Park, H., \& Kim, Y. K. (2016). An empirical test of the triple bottom line of customer-centric sustainability: the case of fast fashion. Fashion and Textiles, 3(1). 
https://doi.org/10.1186/s40691-016-0077-6

Wagner, M. M., \& Heinzel, T. (2020). Human perceptions of recycled textiles and circular fashion: A systematic literature review. Sustainability (Switzerland), 12(24), 1-27. https://doi.org/10.3390/su122410599

Winge, T. M. (2008). Green is the new black: Celebrity chic and the "green" commodity fetish. Fashion Theory - Journal of Dress Body and Culture, 12(4), 511-524. https://doi.org/10.2752/175174108X346968

wood, laura. (2021, January 11). Global Ethical Fashion Market Report 2020: Opportunities, Strategies, COVID-19 Impacts, Growth and Change, 2019-2030 - ResearchAndMarkets.com | Business Wire. https://www.businesswire.com/news/home/20210111005582/en/Global-EthicalFashion-Market-Report-2020-Opportunities-Strategies-COVID-19-Impacts-Growth-andChange-2019-2030---ResearchAndMarkets.com

wood, L. (2020). Global Fast Fashion Market Report (2020 to 2030) - COVID-19 Growth and Change. https://www.globenewswire.com/news-release/2020/06/09/2045523/0/en/Global-FastFashion-Market-Report-2020-to-2030-COVID-19-Growth-and-Change.html 